\title{
Double Wires Submerged Arc Welding Temperature Field Simulation
}

\author{
Chen Jianmin ${ }^{1, ~ a ~}$, Cao Zhenping ${ }^{2, b}$, Li Jun ${ }^{3, c}$, Guo Pengzeng ${ }^{4, d}$ and Sun Yan ${ }^{5, e}$ \\ 1,2,3,4,5 Department of Marine Engineering, China University of Petroleum (East China), Shandong, \\ Qingdao, 266580, China \\ ajmchen1956@126.com, ${ }^{b}$ caozp.cpoe@cnpc.com.cn, 'czgsydxlijun2007@126.com, \\ dsunnyhaber@126.com, ${ }^{\mathrm{e}}$ sunshine3226@126.com
}

Keywords: double wire submerged arc welding; heat source model; temperature field simulation; element's birth and death

\begin{abstract}
Double wires submerged arc welding is more and more widely applied. However, due to the immaturity of the welding process, the quality of double wires submerged arc welding is still not so good, and its application in the offshore platform engineering is limited. The paper adopt the simple flat plate welding, uses the finite element software ANSYS to simulates the temperature field of double wire submerged arc welding process. During the temperature field simulation process, double ellipsoid heat source model is used as a load heat source, composite convection coefficient is adopted to simulate heat loss, the element's birth and death is considered to simulate welding material injection, welding speed is assigned as a constant. At last, a good result of temperature field is obtained.
\end{abstract}

\section{Introduction}

Steel pipe is an important part of offshore platform structure, the development of steel pile manufacturing technology is lagging behind in the domestic, especially the welding process. With the vigorous development of offshore platform engineering, it is very necessary to develop a new welding process to improve the quality and efficiency of the production of the offshore platform pipe.

Double wires submerged arc welding as an efficient welding becomes an important choice for the offshore platform engineering welding. It reduces weld passes and thus improves the welding efficiency greatly.Through adjusting the front and rear wire welding parameters, the input of welding energy can be controlled in a wide range to meet the performance requirements under different use conditions [1]. The double wire submerged arc welding studied in this paper has two power supplies and two welding arc, each wire is powered by a power source independent. It has large penetration and higher deposition rate, the weld metal dilution rate is close to single wire submerged arc welding, so it can improve welding efficiency and welding quality. However, the technology of double wire submerged arc welding is not mature and its welding quality is unstable. In industry demanding high welding quality, such as offshore platform engineering, the application of double wire submerged arc welding is limited to a certain degree. In view of this situation, this paper uses ANSYS software to simulate the temperature field of double wire submerged arc welding, studies the temperature distribution of the two-wire submerged arc welding process and researches the influence of some welding parameters on the welding temperature field.

\section{Finite Element Model}

In this paper, plate butt welding model is used. The plate length is $0.5 \mathrm{~m}$, width is $0.2 \mathrm{~m}$ and thickness is $0.015 \mathrm{~m}$. The edge of plate is V-groove, which is after bottoming welding and lefts $5 \mathrm{~mm}$ flat place. In view of the symmetry, $1 / 2$ model is taken to do the analysis. V-groove consists of two entities, of which one is formed by former wire welding material, another by rear wire welding material.

Specify the material properties for the solid model. Some properties is temperature dependent, such as specific heat capacity, thermal conductivity and so on, therefore, the definition of material 
properties related with temperature is essential. Because temperature gradient is very large at welding part, non-uniform meshing is used to encrypt welding part.

\section{Applying Loads}

Welding Heat Source Model. Establishing Welding heat source model is very important to welding temperature field simulation. In the field of welding simulation, a series of heat source computing models have been established by formers, such as Gaussian surface flux distribution model, hemispherical power density distribution model, ellipsoidal power density distribution model, double ellipsoidal power density distribution model [2], and so on. According to previous studies and experiments, double elliptical heat source model is more reasonable for double wire submerged arc welding simulation. The following is double ellipsoid heat source model expression [3]. Double ellipsoid heat source model is shown in Fig. 1 [4].

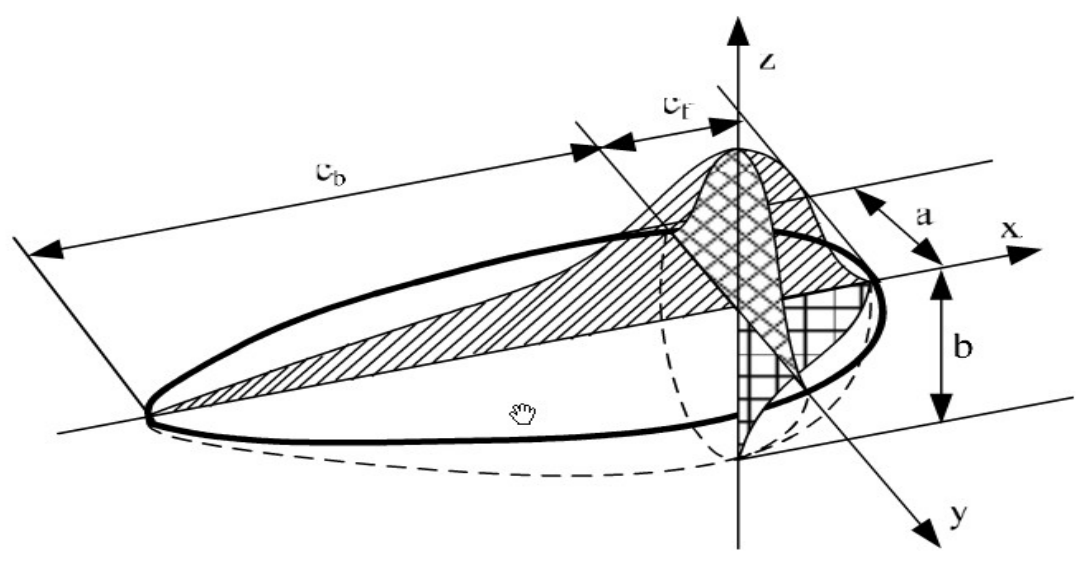

Fig. 1 Double ellipsoid heat source model

The power density distribution inside the front quadrant is:

$$
q(x, y, z, t)=\frac{6 \sqrt{3} f_{1} Q}{a b c \pi^{3 / 2}} \exp \left(-3\left(\frac{x^{2}}{a^{2}}+\frac{y^{2}}{b^{2}}+\frac{(z-v t)^{2}}{c_{f}^{2}}\right)\right)
$$

The power density distribution inside the rear quadrant is:

$$
q(x, y, z, t)=\frac{6 \sqrt{3} f_{2} Q}{a b c \pi^{3 / 2}} \exp \left(-3\left(\frac{x^{2}}{a^{2}}+\frac{y^{2}}{b^{2}}+\frac{(z-v t)^{2}}{c_{b}^{2}}\right)\right)
$$

In Eq. 1 and Eq. 2: a, b, $\mathrm{c}_{\mathrm{f}}, \mathrm{c}_{\mathrm{b}}$ are the shape parameters; $\mathrm{f}_{1}, \mathrm{f}_{2}$ are the power fraction parameters, $\mathrm{f}_{1}+\mathrm{f}_{2}=2$; $\mathrm{v}$ is the welding speed; $\mathrm{t}$ is time; $\mathrm{Q}=\eta \mathrm{UI}, \eta$ is the efficiency of power, $\mathrm{U}$ is the voltage of power, I is the current of power.

Composite Convection Coefficient. In welding process, the temperature of weldment is so high that thermal radiation can not be ignored for welding temperature field simulation. However, the introduction of radiation heat in ANSYS makes simulation quite complex and difficult. In order to both consider the impact of radiation heat and reduce the computational complexity, radiation heat transfer is merged into convective heat transfer in this paper, which is called composite heat transfer coefficient. Composite heat transfer coefficient is an integrated approximation coefficient, whose value depends on temperature. Compared to traditional constant heat transfer coefficient, composite heat transfer coefficient is much closer to the engineering practice and will make the simulation more accurate. The value of composite convection coefficient varied with temperature is shown in the Table 1. 
Table 1 composite heat transfer coefficient [5]

\begin{tabular}{|c|c|c|c|c|c|c|}
\hline temp, $\left[{ }^{\circ} \mathrm{C}\right]$ & 20 & 55 & 95 & 155 & 255 & 335 \\
\hline value, $\left[\mathrm{W} /\left(\mathrm{m}^{2} \cdot{ }^{\circ} \mathrm{C}\right)\right]$ & 10 & 11.8 & 14.3 & 17.6 & 23.3 & 28.9 \\
\hline temp,$\left[{ }^{\circ} \mathrm{C}\right]$ & 475 & 675 & 975 & 1375 & 1975 & 2675 \\
\hline value, $\left[\mathrm{W} /\left(\mathrm{m} 2 \cdot{ }^{\circ} \mathrm{C}\right)\right]$ & 41.5 & 64.1 & 104 & 160 & 197 & 238 \\
\hline
\end{tabular}

\section{Solving Process Controlling}

Element's Birth and Death. The welding process simulation involves welding material input. In order to simulate the material input, this paper uses ANSYS element's birth and death method. In modeling, all elements are created including birth elements and dead elements, and all welded parts element is killed before solving. In the process of solving, the dead elements are activated with time by solving control commands. Thus the dynamic simulation of material input is achieved.

Welding Process Controlling. Most of double wire submerged arc welding are linear welding and its speed is a constant. ANSYS software controls welding process by time. Element's live and death controlling: in modeling, crate birth and death element along the $\mathrm{X}$-axis in order; according to the relationship between welding time and the coordinates of welding rod, it select dead element in the electrode position and then activate the selected element. Double ellipsoid heat source movement controlling: according to the relationship between welding time and the coordinates of welding rod, it controls the position of the heat source center applies heat loads on element in time.

Two Wire Synchronous Controlling. Double wire submerged arc has two wires which moves forward synchronously and leaves some distance between them. The two wires arranged along with the welding direction. For double wire submerged arc welding simulation, two different double ellipsoid heat source is need, and should move with time. Control the positions of the two heat source center by time, and apply the heat load to the corresponding positions through the heat source centers. Two welding place should input weld materials in double wire submerged arc welding, in modeling, crate two weld entities to simulate the front welding part and the rear welding part, in the process of simulation, select corresponding part of the front and the rear welding part element in order through front and rear wire position, then activate them.

\section{Solving and Analysis}

Front double ellipsoid heat source model parameters: front axle $c_{\mathrm{f}}$ is $8 \mathrm{~mm}$, rear axle $\mathrm{c}_{\mathrm{b}}$ is $22 \mathrm{~mm}$, width a is $10 \mathrm{~mm}$, depth $\mathrm{b}$ is $14 \mathrm{~mm}$; rear double ellipsoid heat source model size parameters: front axle $\mathrm{c}_{\mathrm{f}}$ is $7.5 \mathrm{~mm}$, rear axle $\mathrm{c}_{\mathrm{b}}$ is $22 \mathrm{~mm}$, width is $18 \mathrm{~mm}$, depth is $12 \mathrm{~mm}$; solving parameters: welding speed is $0.008 \mathrm{~m} / \mathrm{s}$, the welding power of front wire is $18000 \mathrm{~W}$, the welding power of rear wire is $20000 \mathrm{~W}$, Welding efficiency is 0.85 , the distance between front wire and rear wire is $32 \mathrm{~mm}$. Applying all of parameters to the simulation, then a good result is obtain at last. Temperature field image at moment 10 s is shown in Fig. 2; temperature field image at moment 20s is shown in Fig. 3.

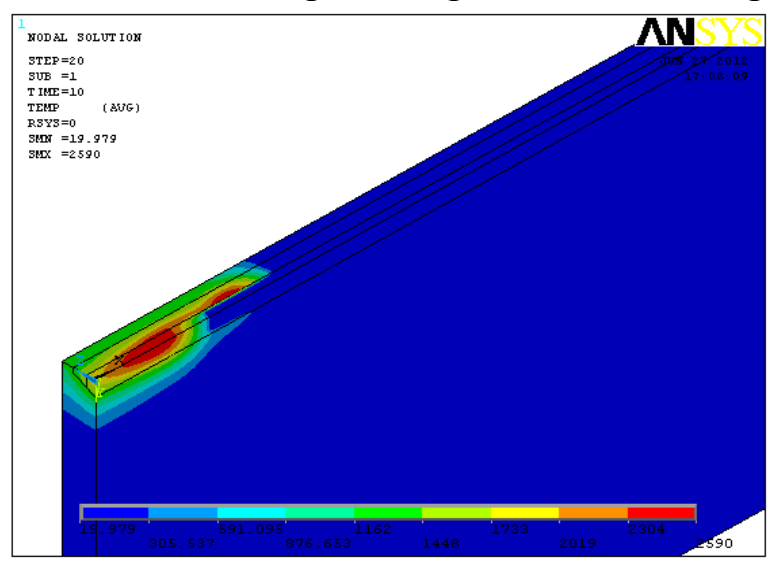

Fig. 2 temperature field image (10s)

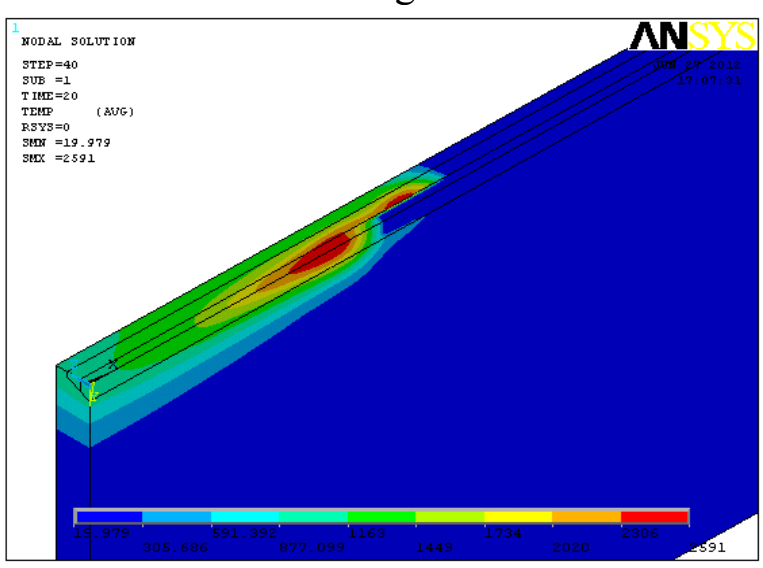

Fig. 3 temperature field image (20s) 
Keeping other welding parameters unchanged, change the distance of two wire to $40 \mathrm{~mm}$ and analysis, capture the 30s temperature field image shown in Fig. 4. Change the distance of two wire to $48 \mathrm{~mm}$ and analysis again, capture the 30 s temperature field image shown in Fig. 5.

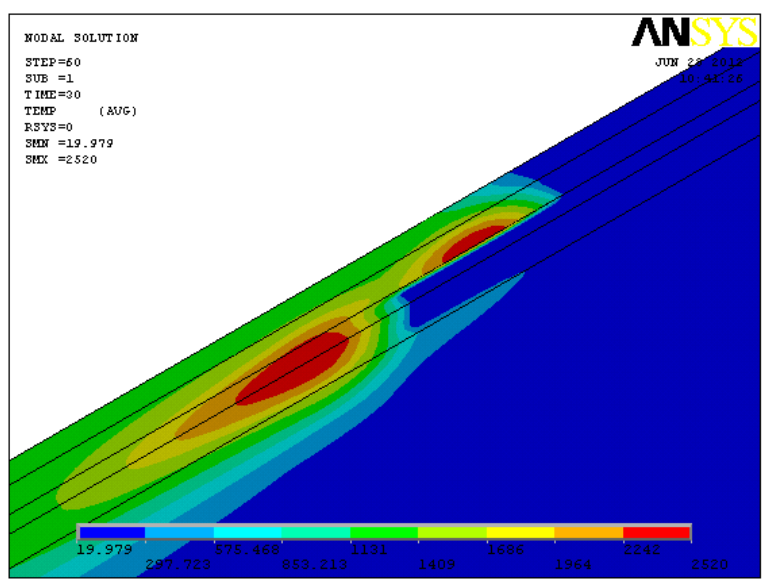

Fig. 4 temperature field image $(40 \mathrm{~mm})$

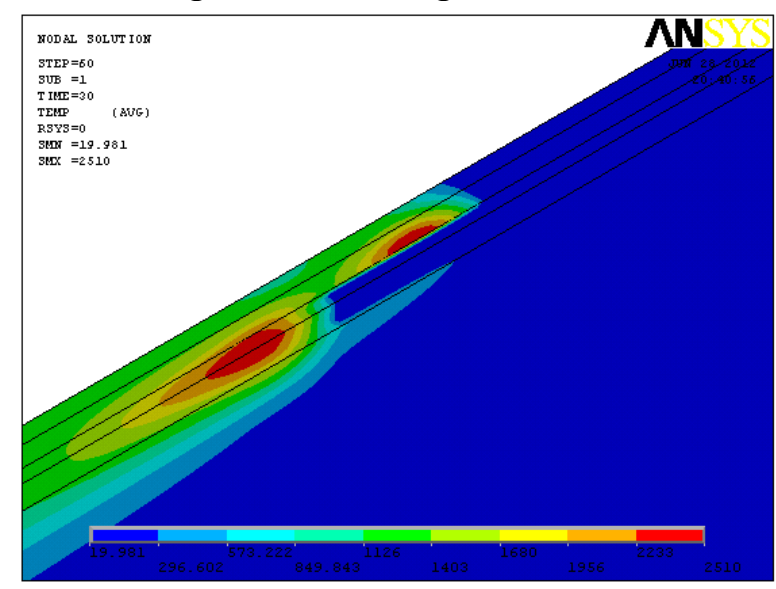

Fig. 5 temperature field image $(48 \mathrm{~mm})$

According to Fig. 4 and Fig. 5, when the distance is $40 \mathrm{~mm}$, the double wire submerged arc welding forms public molten pool which is not very clear; however, when the distance is $48 \mathrm{~mm}$, public molten pool is not formed. So whether public molten pool formed or not, it partly depends on the distance of two wires.

\section{Conclusion}

The paper adopts ANSYS software to simulate double wire submerged arc welding which includes modeling, loading and solving, and then it obtains the change of temperature field in time .Adjusting the parameters of double wire submerged arc welding, a good result which conforms actual welding temperature field is obtained. Change the distance of two wire to $40 \mathrm{~mm}$ and $48 \mathrm{~mm}$ and solve again, then, capture the 30 s temperature field images. From the images, when the distance is less than $40 \mathrm{~mm}$, the double wire submerged arc welding is easy to form public molten pool and has a good welding quality.

\section{Acknowledgements}

This work is financially supported by "the Fundamental Research Funds for the Central Universities"(10CX05005A).

\section{References}

[1] Fu Kuijun, Ji Yumei and Zhai Xiaoli: Influence of welding on microstructure and properties of welded joint using double wires submerged arc welding process. Welding \& Joining, 2004(7), 28-31. [2] John.G: A new finite model for welding heat source. Metallurgual Transactions,1984, 15B(2): 299-305.

[3] Meng Qingguo, Fang Hongyuan, Xu Wenli and Ji Shude: Heat source model for twin wire welding. Chinese of mechanical engineering, 2005, vol 41(4), 110-113 .

[4] Dong Kequan, Liu Chaoying and Chen Yingjun: Research on the loading algorithm of double ellipsoid heat source model. Machinery Design \& Manufacture, 2008(11), 60-62.

[5] Huang Jian, Liu Cungen: Analysis of the combined coefficient of heat transfer in the welding temperature field. Ship Engineering, 2009, vol 31(4), 79-83. 